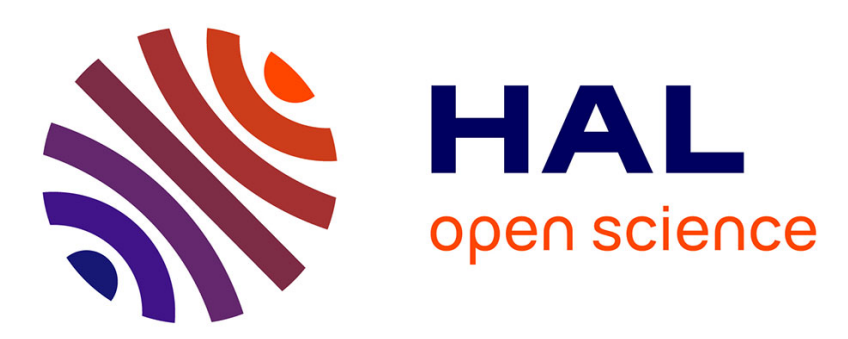

\title{
The growth of Li2B4O7 single crystals and investigation of low temperature elastic anomalies
}

V. Lomonov, P. Senushenkov, I. Silvestrova, Yu. Pisarevsky, A. Vinogradov

\section{To cite this version:}

V. Lomonov, P. Senushenkov, I. Silvestrova, Yu. Pisarevsky, A. Vinogradov. The growth of Li2B4O7 single crystals and investigation of low temperature elastic anomalies. Journal de Physique IV Proceedings, 1994, 04 (C2), pp.C2-199-C2-200. 10.1051/jp4:1994225 • jpa-00252493

\section{HAL Id: jpa-00252493 https://hal.science/jpa-00252493}

Submitted on 1 Jan 1994

HAL is a multi-disciplinary open access archive for the deposit and dissemination of scientific research documents, whether they are published or not. The documents may come from teaching and research institutions in France or abroad, or from public or private research centers.
L'archive ouverte pluridisciplinaire HAL, est destinée au dépôt et à la diffusion de documents scientifiques de niveau recherche, publiés ou non, émanant des établissements d'enseignement et de recherche français ou étrangers, des laboratoires publics ou privés. 


\title{
The growth of $\mathrm{Li}_{2} \mathrm{~B}_{4} \mathrm{O}_{7}$ single crystals and investigation of low temperature elastic anomalies
}

\author{
V.A. LOMONOV, P.A. SENUSHENKOV, I.M. SILVESTROVA, Yu.V. PISAREVSKY and \\ A.V. VINOGRADOV
}

Institute of Crystallography, Russian Academy of Science, ICRAS, Russia

\begin{abstract}
The growth installation and peculiarities of growth $\mathrm{Li}_{2} \mathrm{~B}_{4} \mathrm{O}_{7}$ (LBO) crystals by Czochralsky method have been described in this paper. Experimental results of temperature dependences of ultrasonic velocities for various modes and crystallographic directions were measured and some anomaly in this dependence was discovered. Our results are discussed in comparison with some previous data.
\end{abstract}

$\mathrm{LBO}$ is very promising piezoelectric material due to high electromechanical properties, founding on the temperature compensated cuts and low cost of starting materials. High quality LBO single crystals were grown by both Czochralsky $(\mathrm{Cz})$ [1] and Bridgman (Br) [2] methods.

For LBO growth we used special apparatus which was designed in ICRAS. These installations allow to easily change furnaces and pulling mechanism (depending on needed temperature of the melt, kind and pressure of gaseous medium and growth method). Parameters of chamber are shown in Table 1, ones of pulling mechanism in Table 2 . Using these chambers, pulling mechanisms and different furnaces, we can quickly prepare various configurations of $\mathrm{Cz}$ and $\mathrm{Br}$.

Table 1 : Parameters of growth chambers.

\begin{tabular}{|l|c|c|c|}
\hline & CROT-M & CROT-I & CROT-B \\
\hline Height (mm) & 450 & 600 & 630 \\
Int. diameter (mm) & 260 & 350 & 440 \\
Work pressure (Pa) & & $2-60000$ & \\
\hline
\end{tabular}

These chambers consist of three parts which can be easily separated for motion seeds and furnaces.

Table 2 : Pulling and rotation mechanisms for crystal or crucible.

\begin{tabular}{|l|c|c|}
\hline & A & B \\
\hline Max. pulling range (mm) & 150 & 300 \\
Pulling velocity (mm/hour) & $0.1-9.9$ & $0.1-9.9$ \\
Rotation velocity (rpm) & $15-99$ & $5-99$ \\
\hline
\end{tabular}

While growing LBO two peculiarities have most importance : relatively small density, that requires high precision of weight sensor, and stoichiometric composition of melt.

In first experiments were used $\mathrm{LiOH}, \mathrm{Li}_{2} \mathrm{CO}_{3}, \mathrm{~B}_{2} \mathrm{O}_{3}, \mathrm{H}_{3} \mathrm{BO}_{3}$ as starting materials. The best results were obtained with $\mathrm{Li}_{2} \mathrm{CO}_{3}$ and $\mathrm{H}_{3} \mathrm{BO}_{3}$. Crystals were grown from platinum crucibles on air and 
from graphite crucibles at neutral atmosphere with $<100>$ or $<001>$ oriented seeds. Pulling rate was equal to $0.7 \mathrm{~mm} /$ hour, rotation - $50 \mathrm{rpm}$. The axial gradient near melt was $40 \mathrm{~K} / \mathrm{cm}$, radial gradient $-10 \mathrm{~K} / \mathrm{cm}$. Th rate of cooling of crystal in growth chamber was $20 \mathrm{~K} / \mathrm{hour}$ at the first stage and $50 \mathrm{~K} /$ hour at the last one.

Crystal pulling and rotation mechanism (its parameters are pointed in Table 2) include weight sensor and precise pulling rate gauge. This allows to keep constant diameter of growing LBO crystal up to $80 \mathrm{~mm}$ if using $100 \mathrm{~mm}$ crucible with enough precision.

Crystals grown under optimal conditions were optically transparent, did not include visible defects and had low mechanical stress. But if grown from nonstoichiometric compound, these crystals sometimes became un transparent while cooling in the growth furnace.

Elastic, piezoelectric and dielectric parameters of our crystals at room temperature according to paper [3], devoted to comparative analysis of various author's data, are the most reliable results and not differ from our results of best crystals.

Absolute value of difference between a lot of measured results at room temperature is relatively small. But the view of low temperature dependences of sound velocities sharply differs not only from one author to another, but also in different experiments.

We consider this difference is connected with presence of incommensurate phase under thermocycling, as it is supposed in [4], although existence of incommensurate phase is denied in [5] from NMR experiments and the results of [4] are explained by jumps of charge due to pyroeffect.

We repeated our previous experiments on measuring temperature dependences of sound velocities on the electrically short-circuited crystals, when the influence of pyroeffect may be neglected. On the diagrams one can see that there are same jumps of sound velocity approximatly at the same temperatures, as well as with open crystals. In this experiment, thermocycles were repeated many times and temperature points of such jumps slightly varied within range $-165 . .-145^{\circ} \mathrm{C}$.

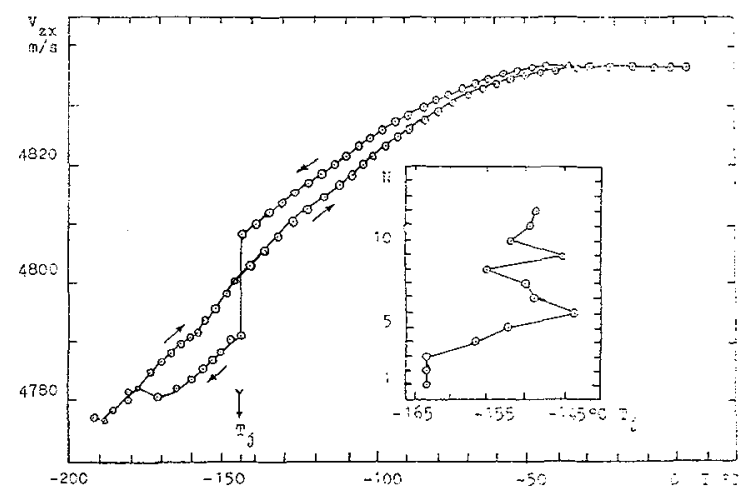

Figure : Temperature dependence of the shear elastic wave velocity propagated along the $z$-axe LBO. The inset shows the dependence of the temperature of the jump in velocity value on the number cooling cycle.

So, wide application of LBO crystals requires new additional investigations of behavior of different parameters at low and high temperatures.

\section{REFERENCES}

1 J.D. Barret, M.N. Iyer, J.E. Greedan, J. Crystal Growth, 41 (1977) 225-32.

2 S.J. Fan, G.S. Shen, W. Wang, J.L. Li and X.H. Le, J. Crystal Growth, 99 (1990) $811-814$

3 J.A. Kosinsky, A. Ballato and Y. Lu, Proc. 1993 IEEE Int.

4 N.D. Zigadlo, V.V. Zaretsky, Sov. Phis. JETP Let., 49, n 9 (1989) 498-500.

5 Yu.V. Ivanov, Ya.V. Burak, K.S. Aleksandrov, Sov. Phys. Solid State, 32, nº 11 (1990) 33793405 . 